Article

\title{
Type II Collagen-Conjugated Mesenchymal Stem Cells Micromass for Articular Tissue Targeting
}

\author{
Shamsul Bin Sulaiman ${ }^{1}$, Shiplu Roy Chowdhury ${ }^{1}$, Mohd Fauzi Bin Mh Busra ${ }^{1}{ }^{\oplus}$, Rizal Bin Abdul Rani ${ }^{2}$, \\ Nor Hamdan Bin Mohamad Yahaya ${ }^{2}$, Yasuhiko Tabata ${ }^{3}{ }^{\circledR D}$, Yosuke Hiraoka ${ }^{4}$, Ruszymah Binti Haji Idrus ${ }^{1}$ \\ and $\mathrm{Ng}$ Min Hwei ${ }^{1, *(1)}$
}

1 Tissue Engineering Centre, Faculty of Medicine, Universiti Kebangsaan Malaysia, Clinical Block, Jalan Yaacob Latiff, Cheras, Kuala Lumpur 56000, Malaysia; sshamsul@ppukm.ukm.edu.my (S.B.S.); shiplu56@gmail.com (S.R.C.); fauzibusra@ukm.edu.my (M.F.B.M.B.); ruszyidrus@gmail.com (R.B.H.I.)

2 Department of Orthopedic \& Traumatology, Faculty of Medicine, Universiti Kebangsaan Malaysia, Clinical Block, Jalan Yaacob Latiff, Cheras, Kuala Lumpur 56000, Malaysia; rizal@ppukm.ukm.edu.my (R.B.A.R.); nhmycj@gmail.com (N.H.B.M.Y.)

3 Department of Biomaterials, Institute for Frontier Medical Sciences, Kyoto University, 53 Kawara-cho Shogoin, Sakyo-ku, Kyoto 606-8507, Japan; yasuhiko@frontier.kyoto-u.ac.jp

4 Biomaterial Group, R\&D Center, Nitta Gelatin Inc., 2-22, Futamata, Yao City, Osaka 581-0024, Japan; yo-hiraoka@nitta-gelatin.co.jp

* Correspondence: angela@ppukm.ukm.edu.my; Tel.: +60-3-914-57679

Citation: Sulaiman, S.B.; Chowdhury, S.R.; Busra, M.F.B.M.; Abdul Rani, R.B.; Mohamad Yahaya, N.H.B.; Tabata, Y.; Hiraoka, Y.; Haji Idrus, R.B.; Hwei, N.M. Type II Collagen-Conjugated Mesenchymal Stem Cells Micromass for Articular Tissue Targeting. Biomedicines 2021, 9 , 880. https://doi.org/10.3390/ biomedicines 9080880

Academic Editors: Raffaele Pugliese and Mike Barbeck

Received: 3 May 2021

Accepted: 9 July 2021

Published: 23 July 2021

Publisher's Note: MDPI stays neutral with regard to jurisdictional claims in published maps and institutional affiliations.

Copyright: (c) 2021 by the authors. Licensee MDPI, Basel, Switzerland. This article is an open access article distributed under the terms and conditions of the Creative Commons Attribution (CC BY) license (https:// creativecommons.org/licenses/by/ $4.0 /)$
Abstract: The tissue engineering approach in osteoarthritic cell therapy often requires the delivery of a substantially high cell number due to the low engraftment efficiency as a result of low affinity binding of implanted cells to the targeted tissue. A modification towards the cell membrane that provides specific epitope for antibody binding to a target tissue may be a plausible solution to increase engraftment. In this study, we intercalated palmitated protein G (PPG) with mesenchymal stem cells (MSCs) and antibody, and evaluated their effects on the properties of MSCs either in monolayer state or in a 3D culture state (gelatin microsphere, GM). Bone marrow MSCs were intercalated with PPG (PPG-MSCs), followed by coating with type II collagen antibody (PPG-MSC-Ab). The effect of PPG and antibody conjugation on the MSC proliferation and multilineage differentiation capabilities both in monolayer and GM cultures was evaluated. PPG did not affect MSC proliferation and differentiation either in monolayer or 3D culture. The PPG-MSCs were successfully conjugated with the type II collagen antibody. Both PPG-MSCs with and without antibody conjugation did not alter MSC proliferation, stemness, and the collagen, aggrecan, and sGAG expression profiles. Assessment of the osteochondral defect explant revealed that the PPG-MSC-Ab micromass was able to attach within $48 \mathrm{~h}$ onto the osteochondral surface. Antibody-conjugated MSCs in GM culture is a potential method for targeted delivery of MSCs in future therapy of cartilage defects and osteoarthritis.

Keywords: gelatin microsphere; MSCs micromass; antibody conjugation; protein G; cell homing

\section{Introduction}

Osteoarthritis (OA) is a chronic degenerative disease of the joints characterized by articular cartilage degeneration of the knee, hip, or hand; synovitis; and the loss of extracellular matrix, accompanied by progressive pain and functional impairment [1]. OA is one of the leading causes of chronic pain and disability, with 17.1 million people living with disability globally [2]. Treatment of OA depends on its severity, and varies from conservative treatment to invasive surgical intervention such as joint replacement [3]. However, due to the risk of failure and morbidity in the conventional treatments, the potential applicability of cell therapy and tissue engineering for treating OA were explored [4].

Cell-based therapies for the treatment of OA are not foreign; numerous studies have reported beneficial effects $[5,6]$. The therapies feature delivery of cells, in particular, mesenchymal stem cells (MSCs) to the knee by means of direct injection or implantation $[7,8]$. 
The desired effects of MSCs therapy in the treatment of OA knees were mostly for its immunomodulatory properties in which it was known that MSCs-based therapies were approved to be used in graft-vs-host disease for immunosuppression [9]. Generally, cell therapies for $\mathrm{OA}$ are safe, albeit their reported efficacy from several randomized trials is quite controversial [10]. This is due to the high variability in the cell preparation and lack of rigors in the trials that preceded its clinical shortcoming [11]. An argument was made, in which the improvements seen among patients in the trials who received MSCs injection were only transient, only to be followed with significant cell apoptosis following injection [12].

The inclination towards cell-based therapies for OA, nonetheless, has led to continued research to tackle major drawbacks. It is known that the MSCs did not survive for long following intra-articular injections [12,13]. Previous reports have shown that MSCs can only survive within a short period of time (within 1-2 weeks) post-injection in addition to the lack of MSCs engraftment to the affected tissue [14,15]. Im et al. in their review recommended that, to solve this, an environment for MSCs to coalesce together in suspension is needed as the communication between cells is paramount for cell survival [12]. Furthermore, the issue with MSCs dispersal and low affinity binding towards the targeted tissue following injection should also be investigated.

With this in mind, cell apoptosis and tissue engraftment could be addressed by the fine tuning of the current tissue engineering approach. The observed cell apoptosis following intra-articular injection is expected due to several reasons; first, the inhabitable inflammatory environment of an OA knee, and second, the inability of MSCs to survive single-handedly in a suspension [12]. The MSCs however, managed to exert their antiinflammatory paracrine effects prior to death $[12,13]$. A provision of non-invasive surface matrix or scaffold for MSCs to attach and grow could prolong their survival and prevent dispersion inside the knee joint, in which the utilization of injectable scaffolds using microspheres may serve as a conceivable solution.

Microspheres are historically known for their role in drug delivery systems and in vitro cellular expansion $[11,16]$. Little was known about their role in cell delivery until several reports demonstrated their safety and efficacy in delivering cells for cartilage regeneration in vivo $[17,18]$. The microsphere is the contact point for the cellular attachment and growth that ensures cell viability while providing a foundation for native chondrocytes to invade and regenerate [19]. Furthermore, a recent study reported that microspheres (specifically gelatin microspheres (GM)) increased the chondrogenic differentiation of mesenchymal stem cells (MSCs) [20]. As microspheres are of miniscule size, microsphere delivery does not require open surgery, as they easily fit inside the needle for intra-articular injection in humans [21]. However, the possibility of the injected microspheres-cells attaching and integrating with the affected tissue following injection remains a significant concern, as this is the first crucial step in cell or tissue regeneration.

Several techniques were developed to improve the homing of cells towards the damaged tissue [22]. These strategies included cell surface modifications that involved: (1) regulating the expression of cell surface receptors, (2) modifying native cell receptors, (3) conjugating new molecules not initially present on the cell surface, or (4) conjugating antibodies to the cell surface.

Previous works have managed to utilize the glycoengineering technique to conjugate antibodies to the cell surface for adherence to the tissue $[23,24]$. In this case, the palmitate conjugate of protein $\mathrm{G}$ acts as the mediator that connects the cell with the antibody.

Therefore, this study was aimed at determining the effect of palmitated protein $G$ (PPG) intercalation and antibody conjugation on MSCs. Here, protein $\mathrm{G}$ was first palmitated (producing PPG), followed by intercalation into the MSCs membrane (PPG-MSCs). The second step involved conjugating type II collagen antibody to the PPG-MSCs. Type II collagen is commonly found in the extracellular matrix of cartilage; hence the antibody conjugation would provide high affinity binding of MSCs to the articular defects. The proliferation and differentiation potentials of both PPG-MSCs and antibody-conjugated 
PPG-MSCs (PPG-MSCs-Ab) in the monolayer and 3D states (GM) were tested. Finally, a preliminary proof of concept of the efficacy of targeted delivery of the PPG-MSC-Ab micromass to an osteochondral defect explant was tested in vitro.

\section{Materials and Methods}

\subsection{Cell Culture and Immunophenotype Analysis}

Ethics approval for this study was granted by Universiti Kebangsaan Malaysia Research Ethics Committee with the approval code UKM PPI/111/8/JEP-2018-458 on 11 October 2018. Bone marrow samples were collected as aspirates from patients undergoing total knee replacement procedures in Hospital Canselor Tunku Muhriz. All patients were informed with a patient information sheet and filled a consent form prior to tissue collection.

Five-ten $\mathrm{mL}$ of bone marrow aspirates $(n=6)$ were harvested, isolated and cultured in monolayer culture using F12: DMEM (1:1) supplemented with 10\% fetal bovine serum (FBS; Biowest, Riverside, MO, USA), $1 \%$ antibiotic-antimycotic (Gibco, Grand Island, NY, USA), $1 \%$ glutamax (Gibco, Grand Island, NY, USA), and 1\% vitamin C (Sigma-Aldrich, St. Louis, $\mathrm{MO}, \mathrm{USA}$ ) (FD). The cells were incubated at $37^{\circ} \mathrm{C}$ in a humidified atmosphere containing $5 \% \mathrm{CO}_{2}$. When the cells began to reach the near confluence stage, they were trypsinized with $0.25 \%$ trypsin $/ 0.1 \%$ EDTA (Gibco, Grand Island, NY, USA) and passaged in $75 \mathrm{~cm}$ culture flasks at low seeding density. Cell cultures from each patient were maintained separately until further usage. For MSCs characterization analysis, the cells were tested at passage 1 until 3 by flow cytometry for surface marker expression to evaluate the stem cells properties according to the International Society of Cellular Therapy (ISCT) guidelines [25]. The cells were harvested with $0.05 \%$ trypsin EDTA, washed with $0.2 \%$ bovine serum albumin (BSA) in PBS, and stained with mouse anti-human CD29, CD44, CD45, CD73, CD90 anti-HLA-DR (BD Pharmingen, San Jose, CA, USA) and CD13 antibodies (Life Technology, Carlsbad, CA, USA). In brief, $2 \times 10^{5}$ cells were suspended in $100 \mu \mathrm{L}$ of $0.2 \%$ BSA in PBS and stained with individual antibodies at a concentration recommended by the manufacturer in separate tubes for $30 \mathrm{~min}$. The cells were then washed with $0.2 \%$ BSA/PBS twice and fixed in $4 \%$ paraformaldehyde. Samples were washed twice in PBS, suspended in $0.2 \%$ BSA/PBS, and analyzed by FACS Calibur cytometer (BD Biosciences, San Jose, CA, USA) using Cell Quest Pro software. Ten thousand gated events were recorded. Gating was determined based on unstained controls.

\subsection{Fabrication of Gelatin Microsphere}

The gelatin microspheres (GM) were fabricated according to an established method [26]. Briefly, $4 \mathrm{~g}$ of gelatin was dissolved in $20 \mathrm{~mL}$ of water and heated up to $60{ }^{\circ} \mathrm{C}$. Two hundred milliliters of olive oil were heated up to $40^{\circ} \mathrm{C}$. Gelatin was then added dropwise into the olive oil while stirring at $420 \mathrm{rpm}$ with a mechanical stirrer. The waterin-oil ( $(w / o)$ emulsion was stirred for $10 \mathrm{~min}$ before being immersed into an ice bath to maintain the temperature at $10{ }^{\circ} \mathrm{C}$ and stirred for a further $30 \mathrm{~min}$. Sixty milliliters of chilled acetone was then added, and the mixture was stirred for another $1 \mathrm{~h}$. The gelatin microspheres were extracted from the olive oil by centrifuging and washing with chilled acetone. The non-crosslinked and dried GM was treated in a vacuum oven at $140{ }^{\circ} \mathrm{C}$ and 0.1 torr for dehydrothermal crosslinking of gelatin according to the method previously reported [27]. GM was characterized for their sizes using an optical microscope and their surface morphology using a scanning electron microscope (SEM). Images were taken using a digital camera attached to the optical microscope, and the sizes were analyzed by measuring the diameters of the microspheres using image QImaging Q-Capture Pro 7 (Surrey, BC, Canada). For imaging under SEM, dry microspheres were mounted onto aluminum stub and sputter-coated with $\mathrm{Au} / \mathrm{Pd}$ and viewed under a scanning electron microscope in the high-pressure mode of $15 \mathrm{kV}$ accelerating voltage. 


\subsection{Cell Coating}

Recombinant protein G (Sigma, St. Louis, MO, USA) was derivatized with N-hydroxy succinimide ester of palmitic acid (Sigma, St. Louis, MO, USA), as previously described [28]. The lipid-derivatized protein G was purified on a $10 \mathrm{~mL}$ Sephadex G-25 (Pharmacia, Piscataway, NJ, USA) column equilibrated with PBS containing $0.1 \%$ deoxycholate (DOC) $\mathrm{pH}-7.4$. The protein concentration was adjusted to $750 \mu \mathrm{g} / \mathrm{mL}$ by OD absorbance at $280 \mathrm{~nm}$, $20 \mu \mathrm{m}$ filter sterilized, and stored at $4{ }^{\circ} \mathrm{C}$ until use. Briefly, in vitro expanded MSCs were incubated in $0.25 \%$ trypsin $/ 0.1 \%$ EDTA (Sigma-Aldrich) for $5 \mathrm{~min}$ at $37^{\circ} \mathrm{C}$, collected, washed three times in serum-free DMEM, and resuspended at a density of $2 \times 10^{6} / \mathrm{mL}$ in DMEM. Varying concentrations of palmitated protein G (PPG) or non-derivatized protein $\mathrm{G}$ (as a negative control) were added to the cell suspension, and the mixture was incubated at $37^{\circ} \mathrm{C}$ for $2 \mathrm{~h}$ with constant gentle mixing. The PPG coated MSCs (PPG-MSCs) were washed in $2 \mathrm{~mL}$ of Hank's balanced salt solution (HBSS) three times, centrifuging at $400 \times g$ for 5 min between each wash. The PPG-MSCs were then incubated in targeting antibody $100 \mu \mathrm{g} / \mathrm{mL}$ per antibody in PBS for $1 \mathrm{~h}$ at $4{ }^{\circ} \mathrm{C}$. The targeting antibodies were antibodies to type II collagen (DSHB Cat:II-II6B3, RRID:Ab 528165, Iowa City, IA, USA). To assess the incorporation of PPG onto MSCs surfaces, cells incubated in different concentrations of PPG in PBS plus $0.1 \%$ DOC or cells incubated in buffer alone for $2 \mathrm{~h}$ were washed twice in the buffer and then incubated at $4{ }^{\circ} \mathrm{C}$ for $1 \mathrm{~h}$ with $100 \mu \mathrm{L}$ (per $1 \times 10^{6}$ cells) of $100 \mu \mathrm{g} / \mathrm{mL}$ of FITC-human IgG (Sigma, Cat: F9512) diluted in PBS plus 0.1\% DOC. PPG-MSCs were washed three times in the buffer and analyzed by flow cytometry and Nikon Eclipse Ti fluorescence microscope (Nikon, Tokyo, Japan).

\subsection{Preparation of Cell Differentiation and Characterization}

GM was sterilized with $70 \%$ ethanol, followed by complete washing with sterilized phosphate buffer saline (PBS; Sigma-Aldrich). PVA (Sigma-Aldrich) with a polymerization degree of 1800 and percent saponification of 88 mole \% was dissolved in PBS. This solution $\left(1 \mathrm{~mL} /\right.$ well) was added into each well of 12 - and 24 -well and incubated at $37^{\circ} \mathrm{C}$ for $15 \mathrm{~min}$. The solution was then removed by aspiration and the well washed with PBS (1 mL/well) twice. For differentiation experiments, the microspheres were transferred to 12-well plates at $10 \mathrm{mg}$ per well, and $5 \times 10^{4} \mathrm{PPG}-\mathrm{MSC}$ s were seeded onto the microspheres per well (i.e., $5 \times 10^{3}$ cells per mg of microspheres). For cell proliferation experiments, the microspheres were transferred to 24-well plates at $2 \mathrm{mg}$ per well, and $1 \times 10^{4}$ PPG-MSCs per well were subsequently seeded onto the microsphere. Presto Blue assay (Thermo Fisher Scientific, Waltham, MA, USA) was applied to study the proliferation of PPG-MSCs on monolayer culture (at day 3 and 5) and GM (at day 1, 3 and 7). All the respective culture and blank plates were rinsed with PBS, and then $180 \mu \mathrm{L}$ of FBS-free medium was added into each plate, followed by $20 \mu \mathrm{L}$ of Presto Blue reagent on top of the FBS-free medium. Later, the plates were incubated for $2 \mathrm{~h}$ at $37^{\circ} \mathrm{C}$ and $5 \% \mathrm{CO}_{2}$. After $2 \mathrm{~h}$ of incubation, $100 \mu \mathrm{L}$ of the supernatant was transferred into a 96-well plate. Subsequently, fluorescence reading was measured using a microplate reader at an excitation wavelength of $570 \mathrm{~nm}$ and an emission wavelength of $600 \mathrm{~nm}$.

\subsection{Evaluation of MSCs Differentiation}

The PPG-MSCs on monolayer and GM were cultured in three different culture media for multilineage differentiation as previously described [20,28,29]. For osteogenic differentiation, MSCs were cultured in FD medium (Gibco, Grand Island, NY, USA) supplemented with $0.1 \mathrm{mM}$ dexamethasone (Sigma-Aldrich, St. Louis, MO, USA), $10 \mathrm{mM}$ b-glycerol phosphate (Sigma-Aldrich, St. Louis, MO, USA), and $0.2 \mathrm{mM}$ ascorbic acid-2-phosphate (Sigma-Aldrich, St. Louis, MO, USA). Induced cells were then replenished with fresh medium every 3 days, and the induction period lasted for 21 days. Differentiation activity was assessed with Alizarin Red staining, which was positively stained for calcium deposition. Briefly, samples were fixed with cold ethanol for $1 \mathrm{~h}$, rinsed with PBS, and stained with Alizarin Red for $1 \mathrm{~h}$. The excess stain was washed off using PBS, followed 
by incubation with boric acid buffer and counterstained with hematoxylin. Samples were dried and evaluated using a bright field microscope (Olympus-CK40, Tokyo, Japan). For quantification purposes, Alizarin Red dye was quantified using a solution of $20 \%$ methanol and $10 \%$ acetic acid in water. After $15 \mathrm{~min}$, the liquid was transferred to a 96-well plate and read on the spectrophotometer at a wavelength of $450 \mathrm{~nm}$.

In chondrogenic differentiation, PPG-MSCs was cultured in FD medium (Gibco, USA) supplemented with serum, 1\% Insulin Transferring Selenium (ITS) (Gibco, Grand Island, NY, USA), $0.2 \mathrm{mM}$ ascorbic acid-2 phosphate (Sigma, USA), $40 \mathrm{ng} / \mathrm{mL}$ L-proline (Sigma, St. Louis, MO, USA), $100 \mathrm{nM}$ dexamethasone (Sigma-Aldrich, St. Louis, MO, USA), $10 \mathrm{ng} / \mathrm{mL}$ transforming growth factor-beta 3 (TGF- $\beta 3$ ) (Invitrogen Inc., Waltham, MA, USA), and $50 \mathrm{ng} / \mathrm{mL}$ insulin-like growth factor 1 (IGF-1) (Invitrogen Inc., Waltham, MA, USA) $[28,30]$. The medium was changed every 3 days, and the induction period lasted for 21 days. The resulting culture was fixed and stained with toluidine blue to identify the presence of proteoglycans using a bright field microscope. Toluidine Blue dye was quantified using a solution made up of $2.5 \mathrm{~mL}$ of concentrated sulfuric acid and $2.5 \mathrm{~mL}$ of water in $95 \mathrm{~mL}$ of methanol. The liquid was transferred to a 96-well plate on a spectrophotometer and measured under a wavelength of $635 \mathrm{~nm}$.

In adipogenic differentiation, MSCs were cultured in FD medium (Gibco, Grand Island, NY, USA) supplemented with $0.25 \mathrm{mmol} / \mathrm{L}$ 3-isobutyl-1-methylxanthine (Sigma-Aldrich, St. Louis, MO, USA), $100 \mathrm{nmol} / \mathrm{mL}$ dexamethasone, and $100 \mathrm{nmol} / \mathrm{L}$ human recombinant insulin (Sigma-Aldrich, St. Louis, MO, USA). The culture medium was changed every 3 days. After day 21, samples were stained with Oil Red O to identify lipid deposition. Briefly, adipogenic cultures were rinsed once with PBS and fixed with 10\% formalin for $60 \mathrm{~min}$ at room temperature. Formalin was discarded, and the cells were stained with $0.36 \%$ Oil Red O for $50 \mathrm{~min}$. The cells were subsequently examined using a bright field microscope. Oil Red O dye was quantified by adding $100 \%$ isopropanol, and incubated for $10 \mathrm{~min}$. The liquid was transferred to a 96-well plate on a spectrophotometer and measured under a wavelength of $500 \mathrm{~nm}$.

\subsection{Immunofluorescence Staining}

The samples were washed with DPBS and fixed with $4 \%$ paraformaldehyde overnight, permeabilized for $20 \mathrm{~min}$ with $0.5 \%$ Triton X-100 solution (Sigma-Aldrich), and then blocked with $10 \%$ goat serum for $1 \mathrm{~h}$ at $37^{\circ} \mathrm{C}$. The cells were incubated with Mouse Anti-Human Collagen II (DSHB Cat:II-II6B3, RRID:Ab 528165) for chondrocytes overnight at $4{ }^{\circ} \mathrm{C}$. The following day, the cells were incubated with Alexa Fluor 594 goat anti-mouse antibodies (Invitrogen) for $1 \mathrm{~h}$ at $37^{\circ} \mathrm{C}$ and counterstained with DAPI (Dako, Glostrup, Denmark) for $15 \mathrm{~min}$. The cells were observed and evaluated with z-stack acquisition using a Nikon Eclipse Ti fluorescence microscope (Nikon, Japan).

\subsection{Measurement of Real-Time PCR}

Total RNA from MSCs, PPG-MSCs, GM-MSCs and GM-PPG-MSCs cultures was extracted using the Qiagen RNeasy mini kit. Concentrations of the extracted total RNA were determined using Nanodrop 2000 spectrophotometer (Thermo Fisher Scientific, Waltham, MA, USA). Complementary DNA (cDNA) was synthesized from the extracted RNA using the Maxima first strand cDNA synthesis kit (Thermo Scientific). The obtained cDNA was used for qPCR, which was performed in triplicates using the SYBR FAST Biorad qPCR master mix (Bio-rad, Hercules, CA, USA). The primers used in the qPCR are given in Table 1. Each sample was run in triplicates. For relative fold gene expression quantitation, the delta delta CT method was used. The CT value was calculated when the fluorescence of the sample exceeded the threshold level. Firstly, the average CT values across the triplicates were obtained for each sample. Then, the delta CT value was generated by normalizing the $\mathrm{CT}$ value of the gene of interest with the CT value of GAPDH. Finally, the relative 
fold change of the mRNA level of the target gene of each sample against the control was calculated as follows:

$$
\begin{gathered}
\text { Relative fold change }=2^{-\Delta \Delta \mathrm{Ct}} \\
\text { where, } \Delta \mathrm{CT}=(\mathrm{CT} \text { target gene }-\mathrm{CT} \mathrm{GAPDH}) \\
\Delta \Delta \mathrm{Ct}=\Delta \mathrm{Ct} \text { (sample })-\Delta \mathrm{Ct}(\text { control })
\end{gathered}
$$

\begin{tabular}{|c|c|c|}
\hline Gen Name & Forward $5^{\prime}-3^{\prime}$ & Reverse $5^{\prime}-3^{\prime}$ \\
\hline Type I Col & AAGGCTTCAAGGTCCCCCTGGTG & CAGCACCAGTAGCACCATCATTTC \\
\hline Type II Col & GGCAATAGCAGGTTCACGTACA & CGATAACAGTCTTGCCCСАCTT \\
\hline Aggrecan & ACTTCCGCTGGTCAGATGGA & TCTCGTGCCAGATCATCACC \\
\hline GAPDH & GGCGATGCTGGCGCTGAGTAC & TGGTTCACACCCATGACGA \\
\hline
\end{tabular}

Table 1. Primer sequences used for real-time PCR experiments.

\subsection{Sulfated Glycosaminoglycan (sGAG) Production Assay}

All samples were digested with a papain digestion solution $(125 \mu \mathrm{g} / \mathrm{mL}$ papain, $5 \mathrm{mM}$ L-cystein, $100 \mathrm{mM} \mathrm{Na}_{2} \mathrm{HPO}_{4}$ and $5 \mathrm{mM}$ EDTA; $\mathrm{pH} 6.8$ ) at $60{ }^{\circ} \mathrm{C}$ for $16 \mathrm{~h}$. Sulfated glycosaminoglycan content was analyzed using a 1,9-dimethyl methylene blue (DMMB) assay (Biocolor, Belfast, UK). A $20 \mu \mathrm{L}$ aliquot of each sample was pipetted into the microplate reader and added with $200 \mu \mathrm{L}$ DMMB. Samples were analyzed immediately by measuring the absorbance at $525 \mathrm{~nm}$ [20].

\subsection{Preliminary Assessment on Articular Cartilage Surface Binding}

Articular cartilage tissues were collected from total knee replacement surgery of the consented patient. Cartilage tissues were excised from the distal femoral condyles. The harvested specimens were cleaned and they were carved into osteochondral explant (OC explant) using a 5-mm biopsy punch. The height of OC explant was around $1 \mathrm{~cm}$. The OC explant were either cultured directly as an explant culture model for subsequent detailed characterization, or else they were processed for the explant co-culture model, using MSCs alone or GM-PPG-MSC-Ab for validation. To perform the explant co-culture, a focal defect of 2.5-mm diameter was first created at the center of the OC explant using a 2.5-mm biopsy punch. After the punch biopsy was created on each explant, the MSCs or GM-PPG-MSC-Ab, both pre-stained with CellTracker Green CMFDA (Molecular Probes Inc, Eugene, OR, USA), were injected to the biopsy site facing upward and let incubated at $37^{\circ} \mathrm{C}$. The explants were then flipped $180^{\circ} \mathrm{C}$ inside the well for the unattached remnants to fall by gravity. After $48 \mathrm{~h}$, the evidence of cell engraftment was assessed via fluorescence microscopy.

\subsection{Statistical Analysis}

Results were expressed as mean \pm standard error of the mean (SEM) and analyzed using two-way ANOVA and Tukey's multiple comparison tests. The differences were considered significant when $p<0.05$.

\section{Results}

\subsection{Stem Cell Characterization}

MSCs appeared spindle shaped in all passages (1 to 3) (Figure 1A). All samples reached confluency within a week. Immunophenotyping of MSCs at passage 1, 2 and 3 was performed using a panel of markers based on the International Society for Cell Therapy guidelines. Flow cytometric analysis confirmed the presence of MSCs in bone marrow cultures as more than $95 \%$ of cells expressed MSC markers, CD13, CD29, CD44, CD73, and CD90 (Figure 1B,C). Less than 5\% of the cells expressed CD45 and the immune activation marker, HLA-DR. The percentage of stem cell marker expression of MSCs was $>90 \%$ at subsequent passages until P3 (Figure 1B,C). 
A
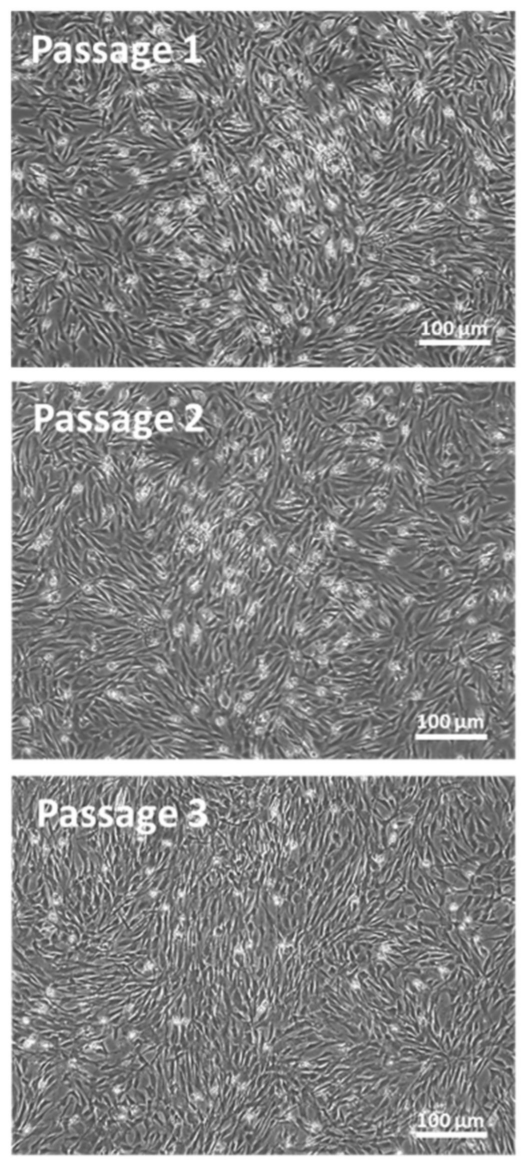

B
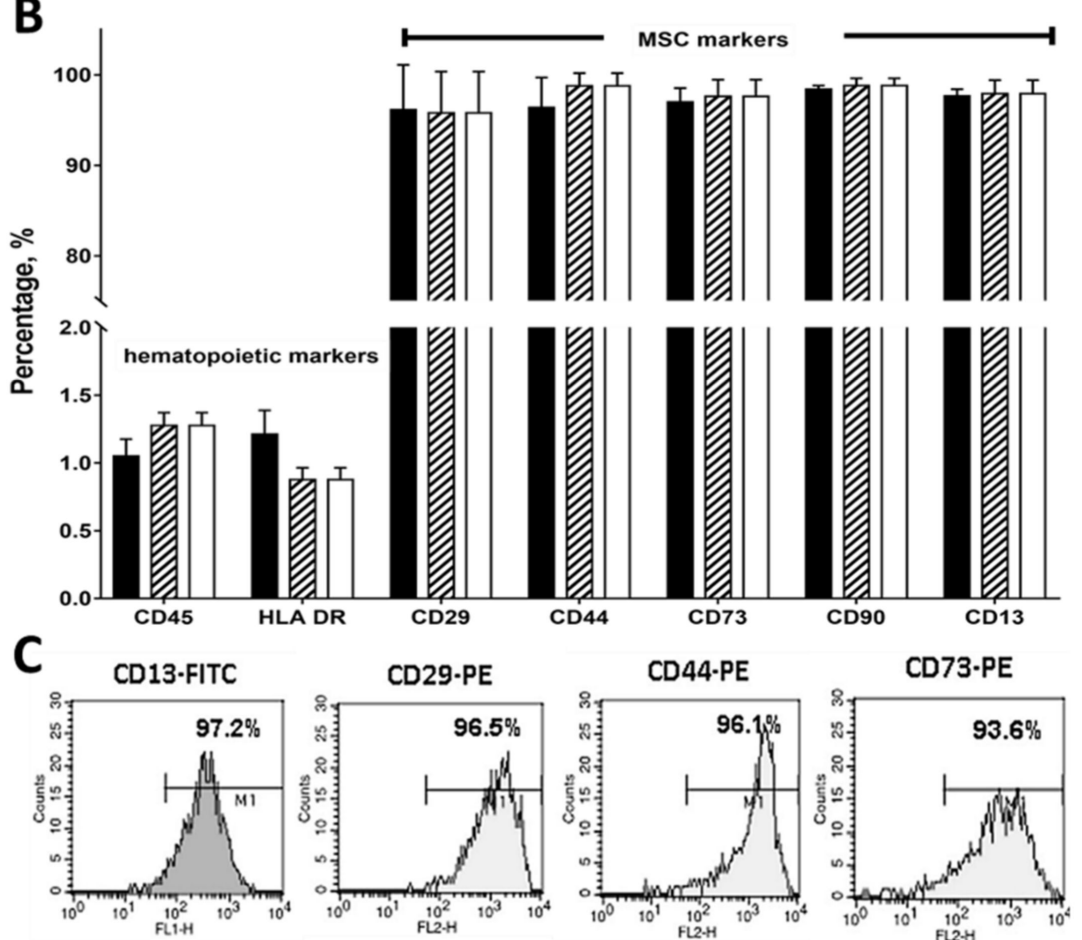

CD73-PE

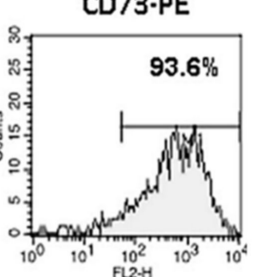

HLA DR-PerCP

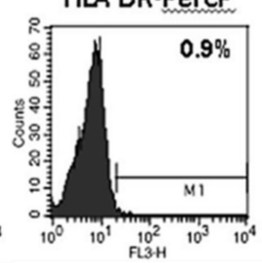

Figure 1. Characterization of Bone-Marrow Stem cells. (A) Morphology of MSCs in 7 days of culture at different passages under the light microscopy. (B,C) Percentage and flow cytometric analysis of MSCs surface markers were tested at passage 1 according to the ISCT guidelines. Scale bars indicate $100 \mu \mathrm{m}$.

\subsection{Effect of Incubation Temperature and Period on Cell Glycosylation}

A test was conducted to determine the relationship between temperature and PPG concentration, at the optimum PPG incubation time. The conjugation of PPG to MSCs showed a concentration-dependent effect at $37^{\circ} \mathrm{C}$, whereby the conjugation could be observed at $50 \mu \mathrm{g} / \mathrm{mL}$ of PPG and intensified until $200 \mu \mathrm{g} / \mathrm{mL}$ (Figure 2A). There was less fluorescence staining in samples incubated at room temperature. Overall, the FITC-IgG $(\mathrm{Ab})$ incorporation increased approximately linearly with increasing PPG concentration at $37^{\circ} \mathrm{C}$, whereby at room temperature, the incorporation was saturated at $150 \mu \mathrm{g} / \mathrm{mL}$. The extent of PPG glycosylation was significantly greater at $37^{\circ} \mathrm{C}$ than room temperature at PPG concentration of 50, 100, 150, and $200 \mu \mathrm{g} / \mathrm{mL}(p<0.001)$ (Figure 2B). 
A
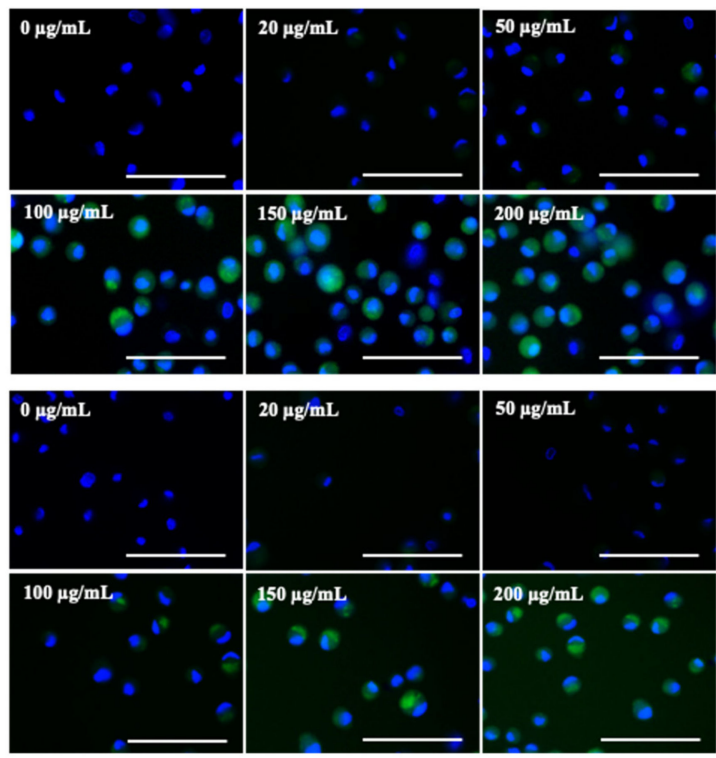

D
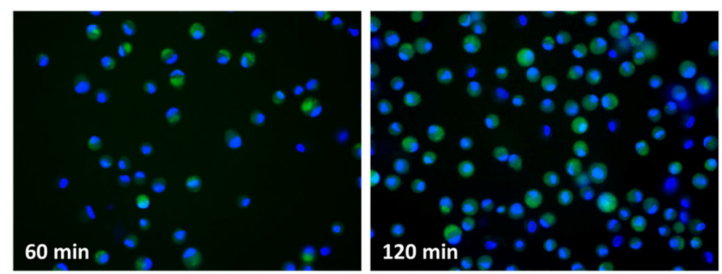

B
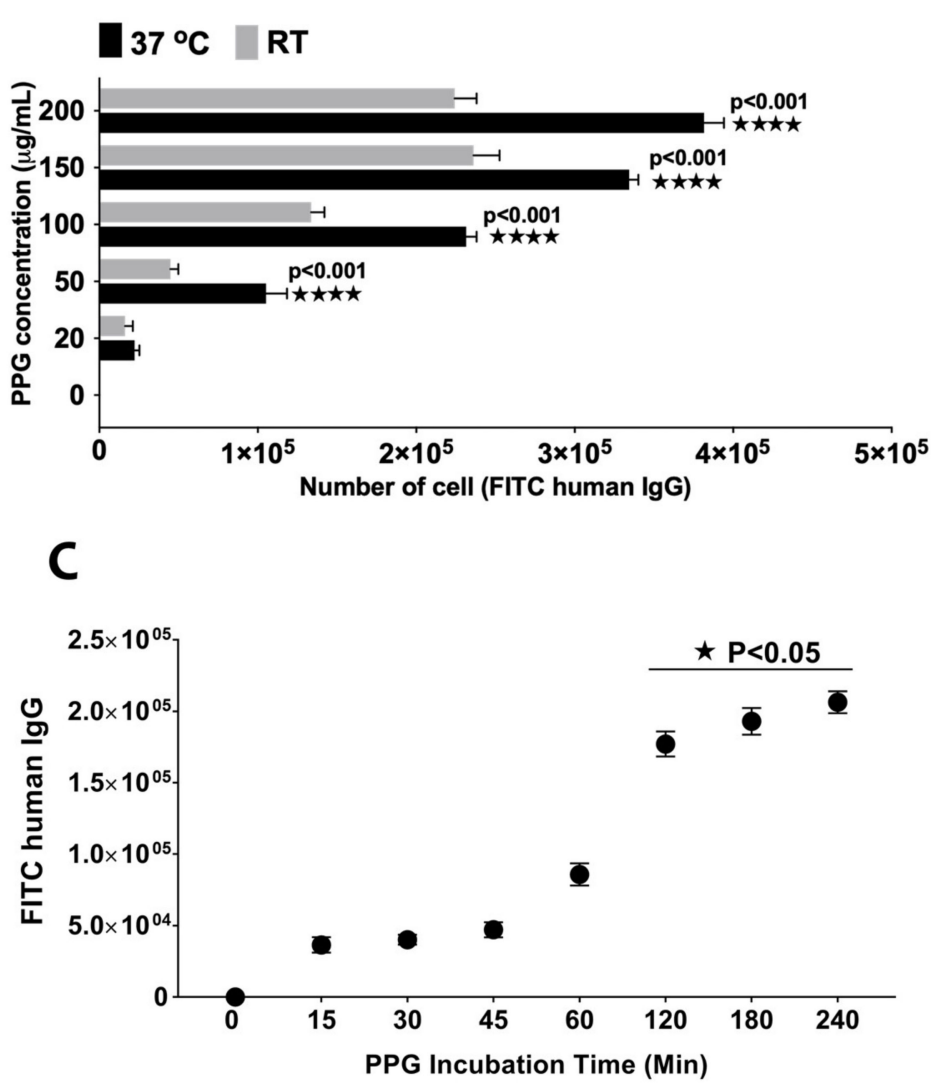

Figure 2. The effect of temperature and PPG concentration on the intercalation of PPG on MSCs. (A) The images show fluorescence staining of MSCs at each concentration of PPG. (B) The bar graph shows the fluorescence intensity of FITChuman IgG at $37^{\circ} \mathrm{C}$ and room temperature with different PPG concentration. (C) The micrograph indicates the MSCs stained with FITC-human IgG at 60 and $120 \mathrm{~min}$. (D) The graph shows the different incubation times on PPG concentrations. Scale bars indicate $100 \mu \mathrm{m}\left({ }^{*} p<0.05,{ }^{* * * *} p<0.001\right)$. The MSCs were counterstained with Hoechst staining (blue).

Next, we tested the effect of the incubation period on the conjugation of PPG to MSCs. PPG's conjugation to MSCs could be measured, starting from minute 15 at $37^{\circ} \mathrm{C}$ (Figure 2D). There was a significant difference in PPG incorporation to the MSCs below $60 \mathrm{~min}$ incubation compared to $120 \mathrm{~min}$ and above (Figure 2C,D). The most optimum time needed for PPG incubation was $120 \mathrm{~min}$. Beyond that, no statistically significant differences were seen.

\subsection{Effect of PPG Coating on MSCs' Proliferation and Differentiation in Monolayer Culture}

Figure 3A shows the effect of PPG conjugation on MSCs on proliferation in monolayer culture. MSCs were able to proliferate despite being conjugated to PPG. No significant changes in terms of MSC' ' proliferation were observed when conjugated with PPG at concentrations 20,50,100,150, and $200 \mu \mathrm{g} / \mathrm{mL}$ at day 3 and day 5, indicating that each PPG concentration does not affect the cell growth as compared to the control $(0 \mu \mathrm{g} / \mathrm{mL})$.

In terms of stemness properties, the PPG-MSCs were able to maintain their multilineage differentiation to osteocyte (Alizarin Red staining), chondrocyte (Toluidine blue staining) and adipocyte (Oil Red O staining) (Figure 3B). Figure 3C shows that PPG-MSCs equally expressed stem cell markers CD44 and CD90 as in normal MSCs. The findings indicated that PPG conjugation does not affect MSCs' stemness.

The effect of PPG conjugation to MSCs on chondrogenic expression is shown in Figure 3D,E. No significant change was observed in terms of sGAG concentration among PPG-MSCs and MSCs (Figure 3D). Also, no substantial changes in gene expression of type 
II collagen, aggrecan, and type I collagen were observed between PPG-MSCs and MSCs group (Figure 3E).

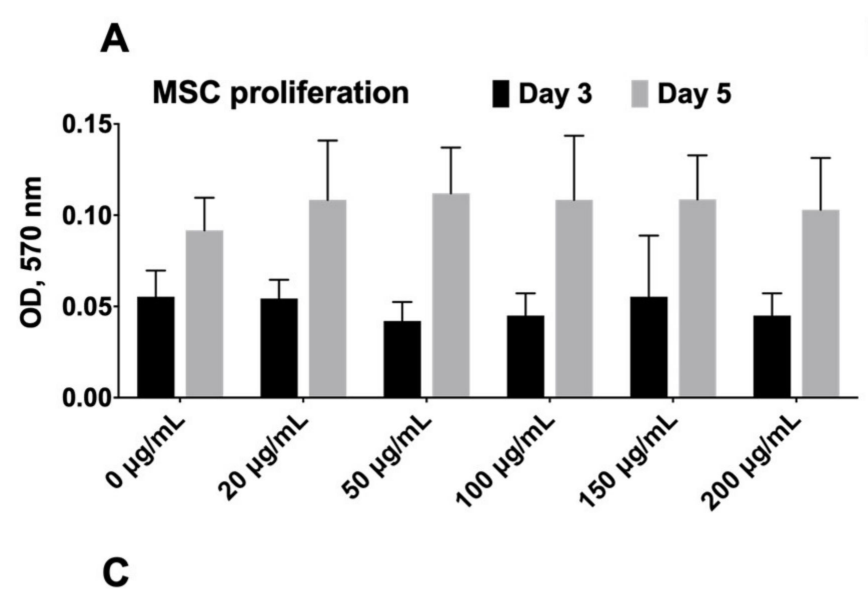

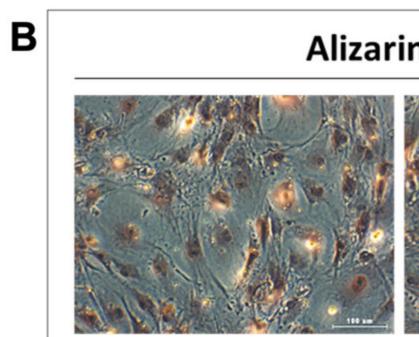

MSC Toluidine Blue
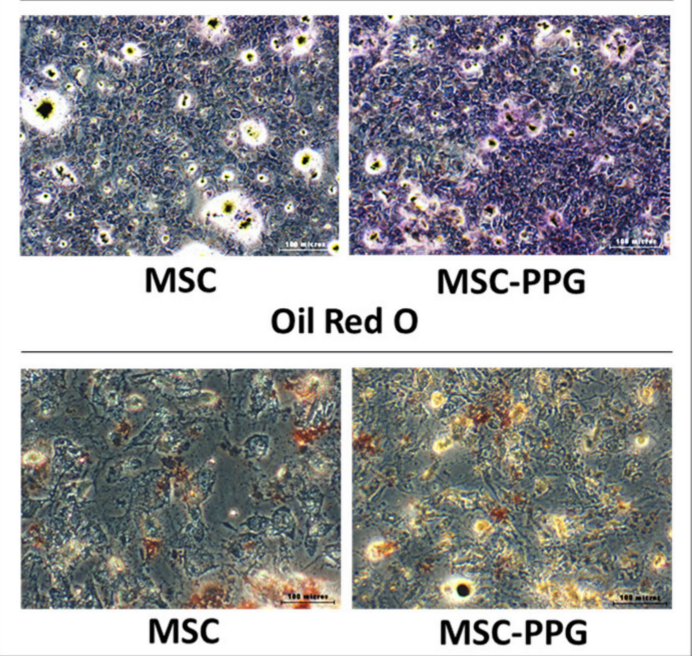

E

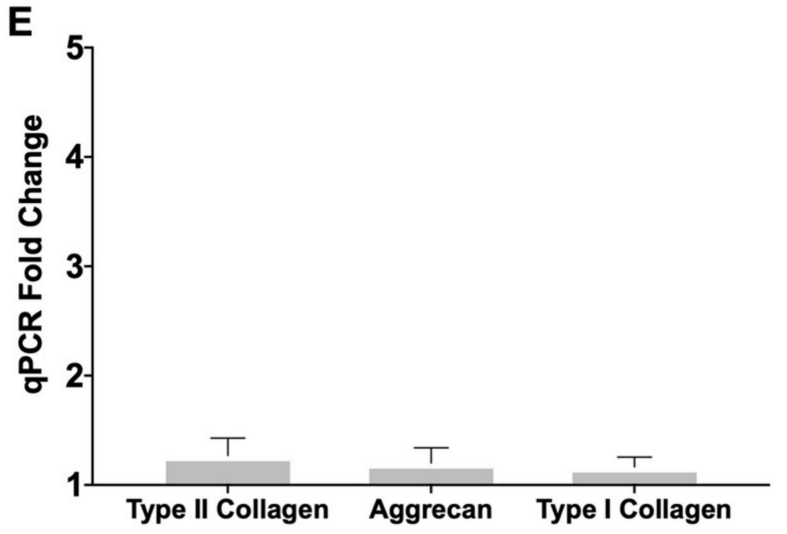

Figure 3. The effect of PPG coating on MSCs' proliferation and differentiation in monolayer culture. (A) Bar graph showing the effect of PPG on MSCs proliferation in monolayer culture (B) The effect of PPG on multilineage differentiation with Alizarin red for osteocytes, Toluidine blue stain for chondrocytes and Oil Red O stain for adipocytes. (C) Bar graph showing the stemness marker CD44 and CD90 between MSCs and PPG-MSCs in the monolayer culture. (D) The effect of PPG on sGAG production in the monolayer culture. (E) The chondrogenic gene expression (fold change) of PPG-MSCs relative to the MSCs (control group).

\subsection{Effect of PPG on MSCs' Proliferation and Differentiation in 3D Culture}

The GM were spherical with uniform sizes, and the surfaces were smooth (Figure 4A). They were translucent and tended to swell once immersed in water and turned transparent. The mean wet diameters of microspheres were 105.1 $\pm 4.6 \mu \mathrm{m}$. The MSCs, when cultured with GM, took as early as $1 \mathrm{~h}$ of incubation to attach. 
A

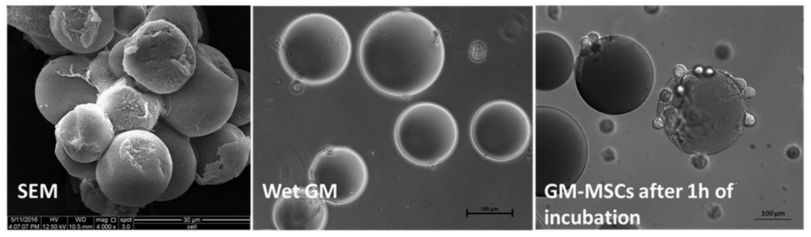

B

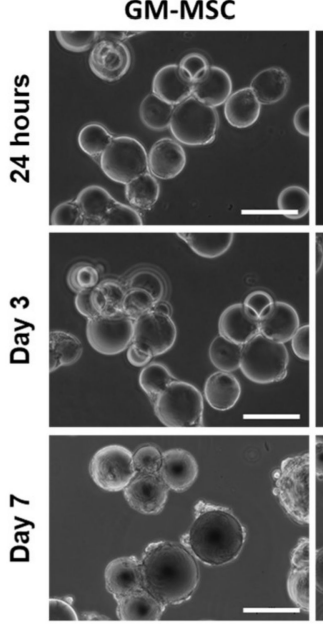

D Toluidine blue

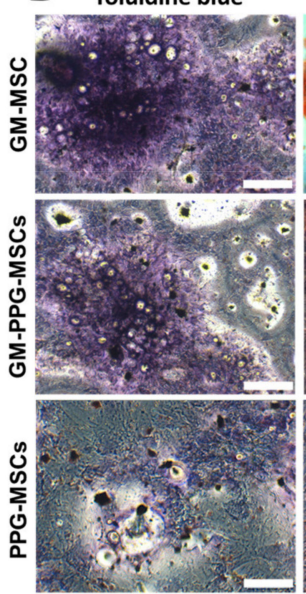

GM-PPG-MSCs

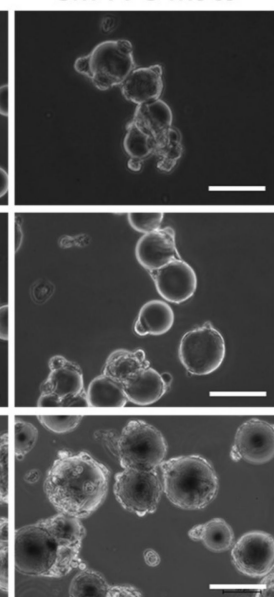

Alizarin Red

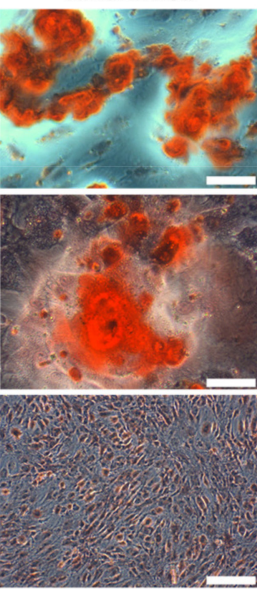

PPG-MSCs

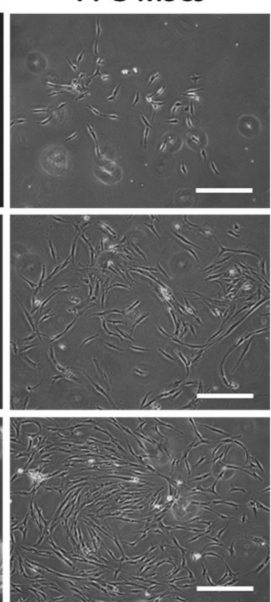

Oil Red 0

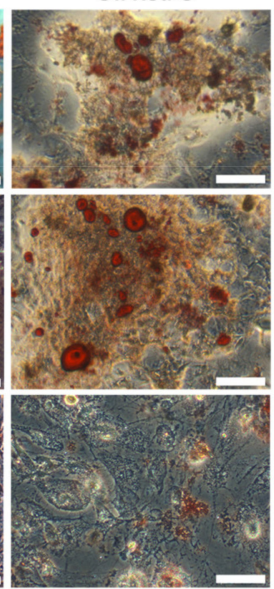

C

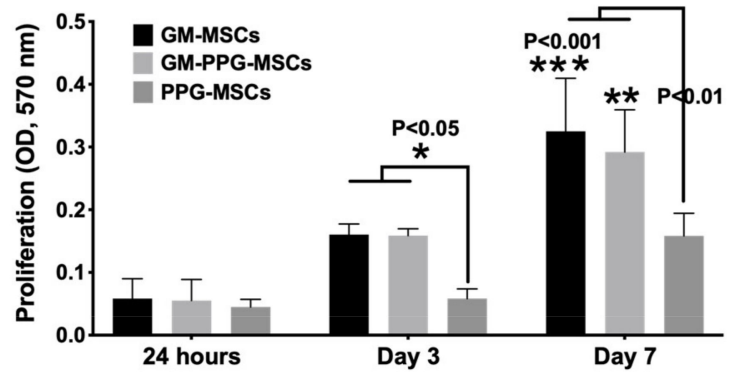

E

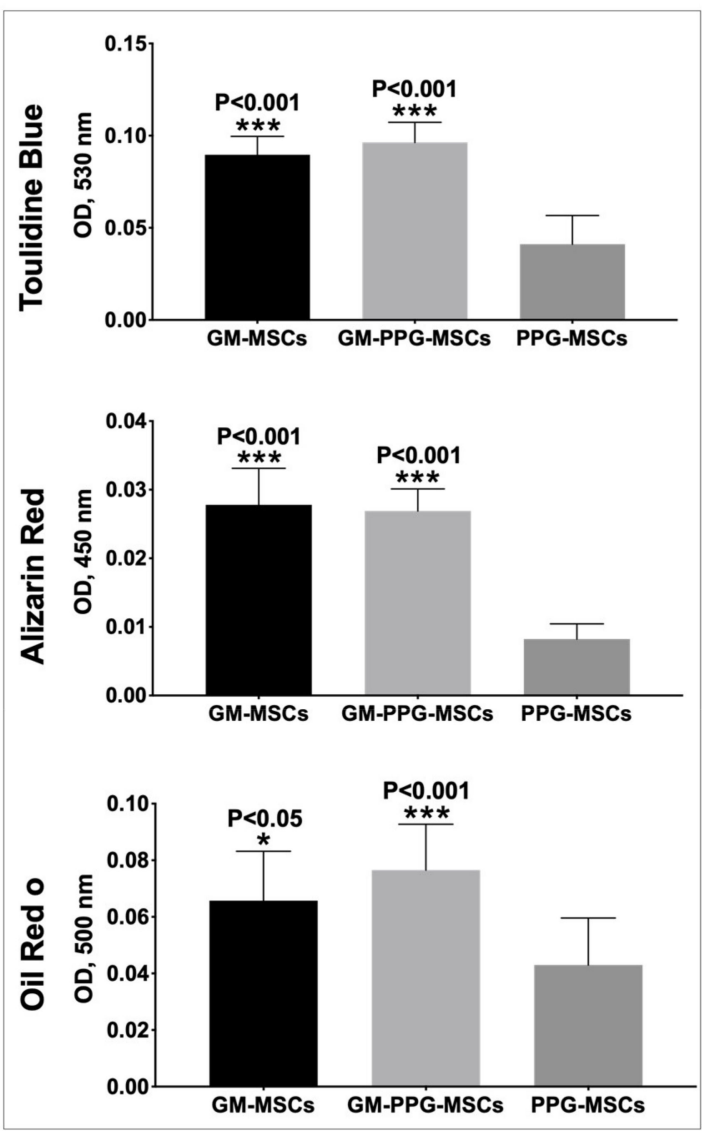

Figure 4. The effect of PPG on MSCs' proliferation and differentiation in 3D culture. (A) Scanning electron microscopy of the GM. (B) The morphology of GM-MSCs as compared to the monolayer culture following day 1, 3 and 7 in culture. (C) The effect of PPG on MSC proliferation in a 3D culture. (D) The effect of antibody conjugation on multilineage differentiation of MSCs in a 3D culture. (E) Spectrophotometry for staining indicates that both 3D culture groups GM-MSCs and GM-PPGMSCs groups significantly increased the staining of all lineage differentiation compared to the monolayer PPG-MSCs group. Scale bar measures $100 \mu \mathrm{m}\left({ }^{*} p<0.05,{ }^{* *} p<0.01,{ }^{* * *} p<0.001\right)$.

The effect of PPG-MSCs' proliferation and differentiation in a 3D culture instead of a monolayer culture was studied. The proliferation of PPG-MSCs in 3D suspension for 1, 3 , and 7 days of culture was observed. Microscopic observation showed that MSCs were well attached to the GM's surface, and there were aggregates formation among the GM (Figure 4A). During the first $24 \mathrm{~h}$ of culture, the number of cells among the GM-MSCs, GM-PPG-MSCs, and PPG-MSCs groups were similar (Figure 4B). On days 3 and 7, both GM-MSCs and GM-PPG-MSCs groups had significantly higher cell proliferation than monolayer PPG-MSCs groups, as expected $(p<0.05)$ (Figure $4 C$ ). However, no significant 
MSC s' proliferation between GM-MSCs and GM-PPG-MSCs groups was observed from day 1 to $7(p>0.05)$.

Figure $4 \mathrm{D}$ showed a significant increase in the extracellular matrix and minerals production (demonstrated by the increased staining of Toluidine blue, Alizarin red, and Oil Red O) in both 3D culture groups (GM-MSCs and GM-PPG-MSCs) as compared to the monolayer culture $(p<0.05)$. Both GM-MSCs and GM-PPG-MSCs groups maintained their multilineage differentiation as they positively differentiated into adipocytes, osteocytes, and chondrocytes through mesodermal multilineage staining (Figure 4E). This indicated that PPG conjugation did not alter the multilineage differentiation of MSCs in monolayer and 3D culture.

Figure 5A shows increasing fluorescence staining of type II collagen following days of culture in the GM-MSCs and GM-PPG-MSCs groups. There was a significant increase in sGAG concentration and collagen type II gene expression in both 3D culture groups (GM-MSCs and GM-PPG-MSCs) in comparison to the monolayer PPG-MSCs group (Figure 5B,C). However, SGAG and type II collagen remained insignificant between GM-MSCs and GM-PPG-MSCs $(p>0.05)$, indicating that PPG also did not affect the chondrogenic differentiation of MSCs in 3D culture.
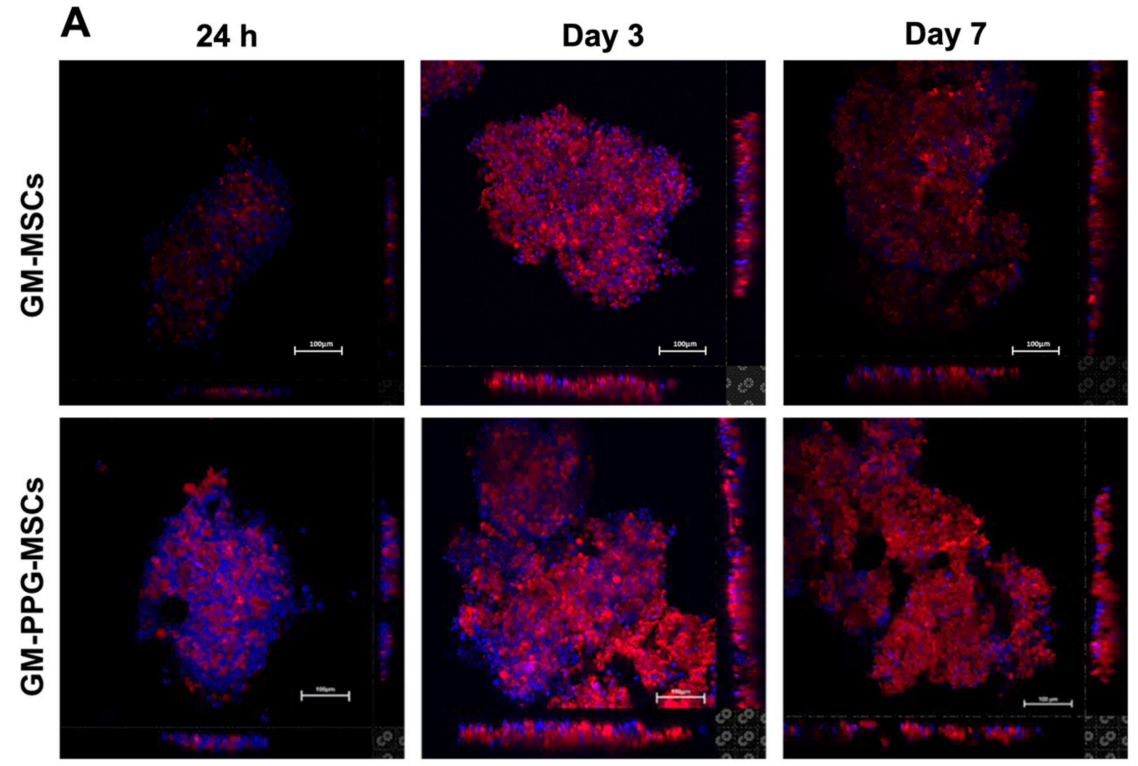

B

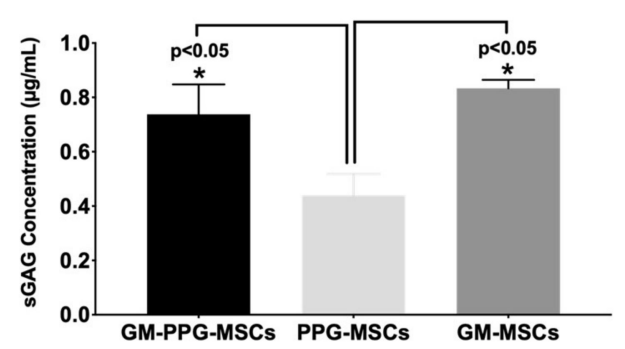

C

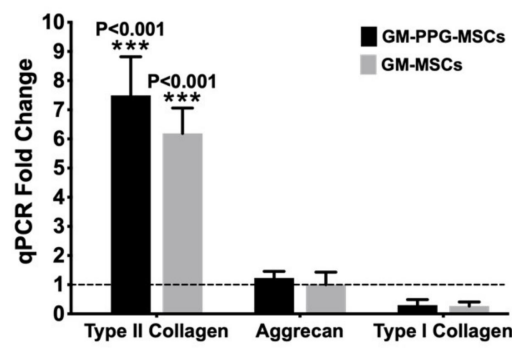

Figure 5. The effect of PPG on MSCs' chondrogenic differentiation in a 3D culture. (A) Immunofluorescence staining of type II collagen indicates increased expression from day 1 to day 7 . The bar graph shows (B) the sGAG production and (C) chondrogenic gene expression of MSCs in 3D culture. Only type II collagen gene expression is significantly increased in GM-PPG-MSCs and GM-MSCs group relative to the PPG-MSCs group (control). Scale bar measures $100 \mu \mathrm{m}\left({ }^{*} p<0.05,{ }^{* * *} p<0.001\right)$. 


\subsection{Conjugation of Antibody on PPG-MSCs in 3D Culture}

Figure 6A shows the efficiency of type II collagen antibody conjugation to the surface of PPG-MSCs. Immunofluorescence staining for anti-collagen type II was detected on day 3 and maintained until day 7, indicating effective conjugation of antibody to PPG. Antibody conjugation to PPG did not affect the MSCs as they attached and proliferated well on GM as comparable to the control group (Figure 6B).

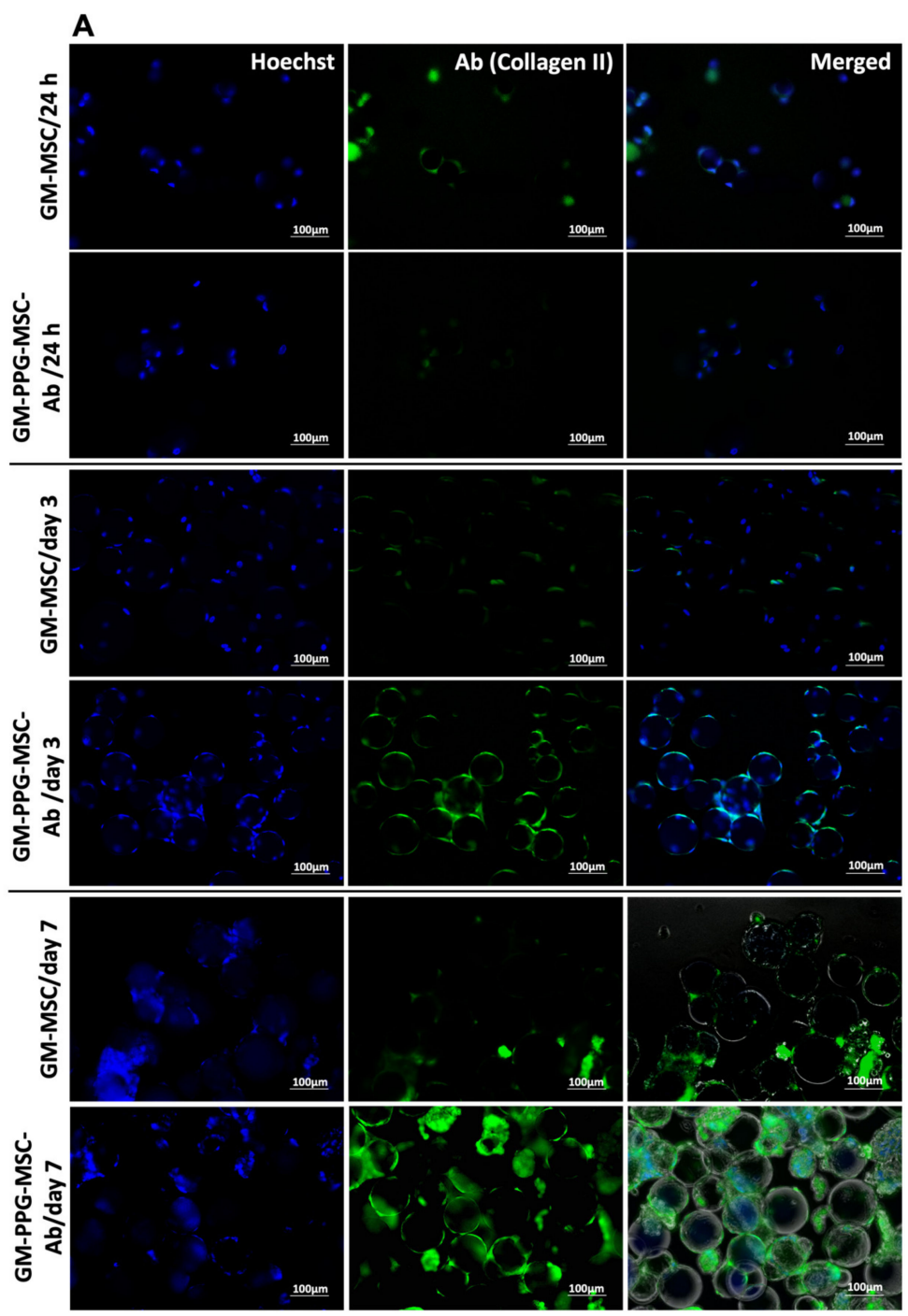

B

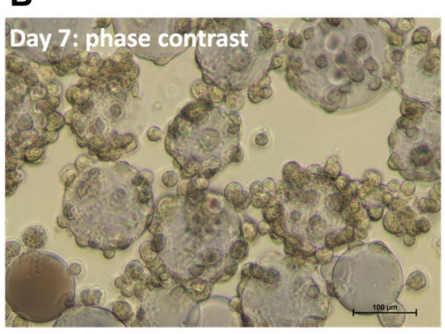

GMD-PPG-MSC-Ab

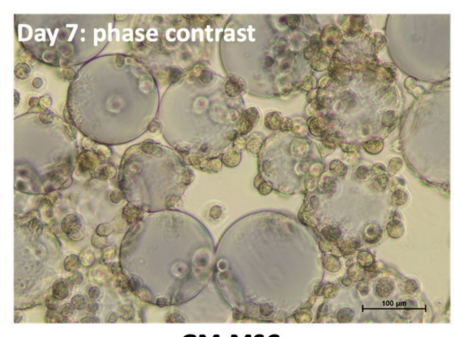

GM-MSC

Figure 6. The efficiency of antibody conjugation to GM-PPG-MSCs. (A) Immunofluorescence staining of Hoechst dye (nucleus staining) and green fluorescent staining of type II collagen on a 3D culture. (B) Phase-contrast images of GM-PPG-MSCs-Ab and GM-MSCs groups that show MSCs attachment and proliferation on the surface of the GM. Scale bar measures $100 \mu \mathrm{m}$. 


\subsection{Preliminary Assessment on Articular Cartilage Surface Attachment}

After $48 \mathrm{~h}$ of incubation of MSCs onto the human osteochondral defect explant, GMPPG-MSCs-Ab could be seen attaching on the osteochondral surface. Figure 7 demonstrated a clear distinction in binding capacity between the group injected with MSCs alone and GM-MSC or GM-PPG-MSCs-Ab. There is a significant increase in green fluorescence intensity in GM-PPG-MSCs-Ab compared to GM-MSCs.
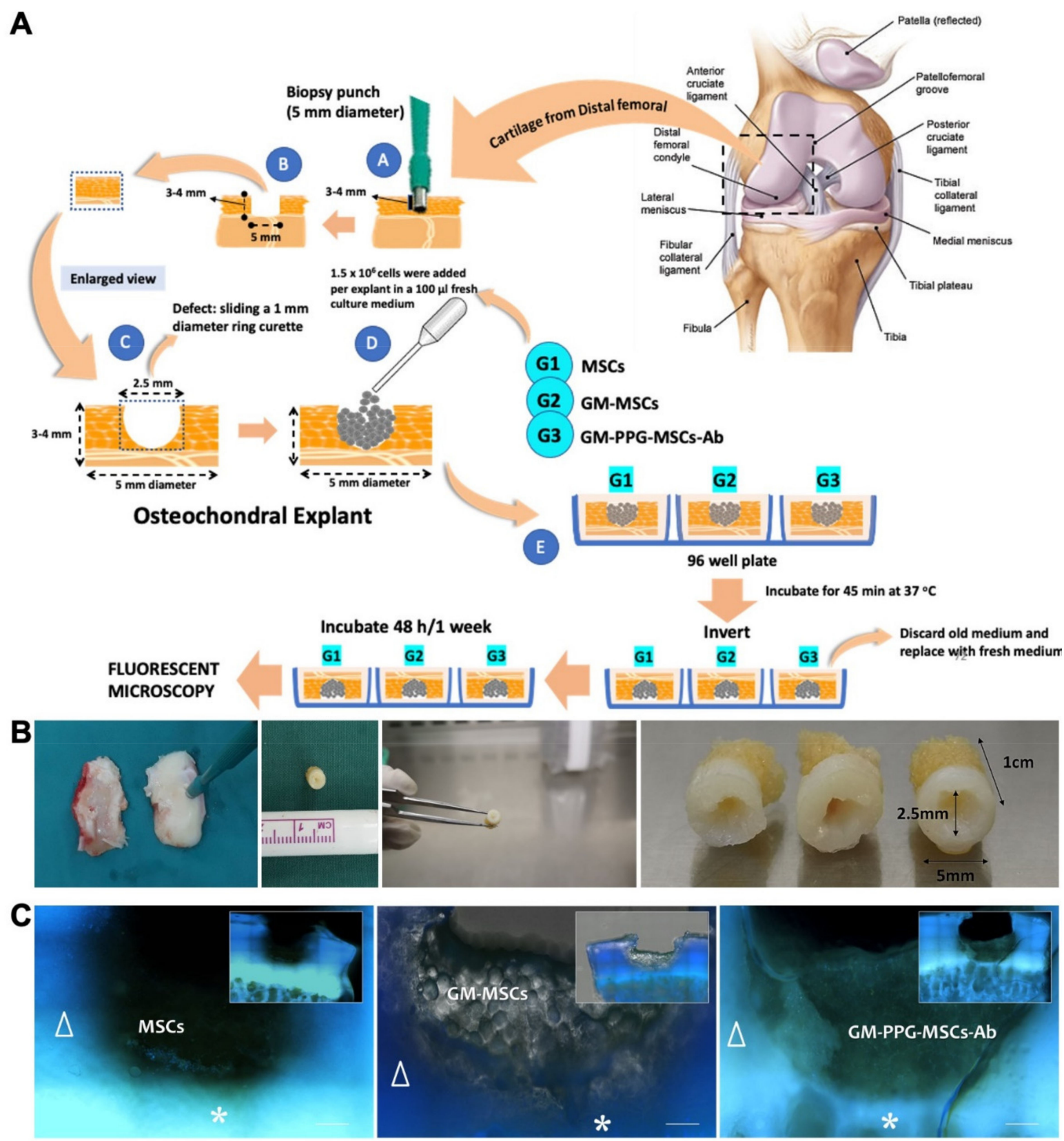

Figure 7. Preliminary assessment on articular cartilage explant. (A) Diagram shows the design flow of ex vivo implantation of MSCs, GM and GM-PPG-MSCs-Ab to osteochondral explant. (B) Figures showing the osteochondral explants. The explants were harvested using 5-mm punch biopsy producing a $1 \times 0.25 \times 0.5 \mathrm{~cm}$ in dimension (C) Immunofluorescence images of osteochondral explants incorporated with MSCs, GM-MSCs and GM-PPG-MSCs-Ab. Scale bar measure $300 \mu \mathrm{m}$. $\triangle$ 一osteochondral explant, *-subchondral region. 


\section{Discussion}

This study highlights the effect of PPG and antibody conjugation on MSCs in monolayer and 3D culture. We demonstrated the application of glycoengineering in cell surface modification to improve targeted delivery for potential use in cartilage disease. The PPG coating did not affect MSC proliferation and differentiation in both monolayer and 3D culture. This indicates that the PPG coating is safe and effective for cell delivery.

Cellular homing is the concept of the tight integration of cells to the native tissue through intercellular adhesion [31]. There were conflicting findings in the ability of MSCs to attach to the affected tissue. In the case of MSCs delivery in OA, several studies reported the disappearance of MSCs in the joint and also at the osteoarthritic site, demonstrating their lack of integration and attachment [14,15]. To improve cell attachment, we attempted to engineer antibody conjugation to MSCs to aid the ligand binding of a specific antigen on the targeted tissue. To do this, we first conjugated protein G to the surface of MSCs, which served as the docking point for antibody conjugation to the cell through palmitation.

Palmitation or palmitoylation is a technique that describes the covalent binding of fatty acids such as palmitic acid (palmitate) to protein residues that are mainly found in cell membrane proteins [32]. Proteins can be covalently modified with various lipids; palmitic acid is an example [32]. Due to the affinity binding of protein $G$ towards the $F_{C}$ region of the antibody, protein $\mathrm{G}$ is an ideal candidate for mediating antibody conjugation to the cell surface [33]. Its counterpart, protein A, can also be utilized but has a lower affinity [34]. For antibody conjugation, we selected type II collagen antibody for site-specific targeted approaches, as type II collagen is the major extracellular matrix component of cartilage [35].

As the mediator for antibody-cell conjugation, the protein conjugation technique has been historically referred to as "cell painting" [36]. The intercalation of protein A or G after derivatization with palmitate to the cell surface or membrane can herald various potentials to be used for multiple applications. The protein can be fused with the Fc region of various antibodies to enhance site-specific delivery. Protein $G$ was experimented with immunoconjugation antibodies to gold-gold sulfide nanoparticles in photothermal cancer therapy [37]. Centi and colleagues utilized protein $G$ with gold nanorods for potential use in biosensing in nanomedicine [38]. Furthermore, in relation to the present study, previous works demonstrated that chondrocytes can be successfully coated with antibodies to chondroitin 4-sulfate and type II collagen via protein G [24].

Cell coatings with PPG are bound to be affected by multiple factors such as temperature and time. To maximize PPG coating in the culture environment, we investigated the effects of temperature in relation to the PPG concentration and incubation time. The initial result showed that PPG coating at $37^{\circ} \mathrm{C}$ was better compared to that at room temperature. In addition, our results also show that the PPG coating could be detected under a fluorescence microscope starting at a concentration of $20 \mu \mathrm{g} / \mathrm{mL}$ at $37^{\circ} \mathrm{C}$, and became more intense at higher PPG concentrations. On the other hand, the optimum incubation time for PPG was $120 \mathrm{~min}(2 \mathrm{~h})$, as suggested previously [23]. Beyond $2 \mathrm{~h}$, no significant differences were noted.

Another aim of this study was to investigate whether the PPG coating is toxic and affects MSCs stemness in both monolayer and 3D culture. The results demonstrated no significant reduction/change in MSCs proliferation and stemness properties. The multilineage abilities of the MSCs were unaltered, as shown by the lineage differentiation staining of Alizarin Red for osteocytes, Toluidine blue for chondrocytes, and Oil Red $\mathrm{O}$ for adipocytes.

The next aim was to test the efficacy of collagen type II conjugation to the PPG-MSCs. We successfully incorporated the antibody to PPG-MSCs from day 1 to 7 , as shown in Figure 6A. Further, MSC proliferation and attachment on GM with/without antibody conjugation were similar, thus suggesting the inert effect of the antibody on the cells. Previous studies also demonstrated successful antibody conjugation with PPG. As shown by Dennis and colleagues, chondroitin 4-sulfate antibody, keratan sulfate antibody, and type II collagen antibody were successfully conjugated to the auricular chondrocytes of rabbits [23]. Ko and co-workers successfully conjugated ICAM-I antibody to MSCs to enhance delivery 
to endothelial cells [34]. On the other hand, Lo et al. were able to incorporate 19Fc [FUT7+] to PPG on cardiosphere-derived cells and MSCs for endothelial attachment [29].

In the present study, we also compared the effect of monolayer and 3D culture environments on MSCs. Factors such as high cell density and chondrocyte phenotype maintenance are vital for ensuring successful tissue regeneration upon delivery. Chondrocytes may undergo dedifferentiation and lose their ability to produce hyaline cartilage for tissue restoration; they might instead form the undesirable fibrocartilage [39-42]. Here, we demonstrated the preservation of the MSCs ability to proliferate and differentiate chondrogenically in both monolayer and 3D culture. In addition, the present findings also confirm the increase of chondrogenic effects by MSCs in the 3D culture as seen in the previous study [25]. Microspheres, specifically gelatin microspheres, drive MSC proliferation and chondrogenic differentiation [19,20,43-45]. These reports indicate that microspheres might aid the maintenance of cell viability and phenotype. On the other hand, we also found that incubating the MSCs with PPG did not affect their proliferation and differentiation regardless of the cell culture environments (i.e., monolayer and 3D), demonstrating the inert effect of PPG on cell biology.

Several issues need to be addressed before we can prove that this product is suitable for use in clinical settings. We have not demonstrated the efficacy of the binding to the targeted tissues in vivo. However, our preliminary data showed that there is significant increase in binding capacity of both GM-MSCs and GM-PPG-MSC-Ab to the hyaline cartilage explants ex vivo in comparison to the MSCs alone (Figure 7). Although, it was difficult to discern a difference between the binding capacity of GM-MSCs and GM-PPG-MSCs-Ab based on the amount of GM bound to the explants in this 2D qualitative assessment, the increase in fluorescence intensity in GM-PPG-MSCs-Ab compared to GM-MSCs suggests that the GM-PPG-MSCs-Ab bound to the affected site is higher. Nevertheless, a 3D quantitative assessment and further investigations involving in vivo models are warranted in the future to prove the binding efficacy and effectiveness of the construct in cartilage regeneration.

\section{Conclusions}

We demonstrated that coating the cell surface with PPG does not interfere or affect the proliferation and stemness profile and differentiation ability of MSCs. Furthermore, culturing MSCs in a 3D culture (GM) is an efficient technique for driving MSC proliferation and differentiation compared to monolayer culture. We also successfully conjugated a collagen type II antibody to the GM-PPG-MSCs and further demonstrated in a preliminary assessment the ability of the Ab-coated MSCs to bind to an articular cartilage surface. These results suggest that GM-PPG-MSCs-Ab is a viable strategy for future targeted cell delivery.

Author Contributions: Conceptualization, S.B.S., S.R.C., N.M.H. and R.B.H.I.; methodology, S.B.S., S.R.C., N.M.H. and R.B.H.I.; validation, S.R.C., N.M.H. and R.B.H.I.; formal analysis, S.B.S., S.R.C., N.M.H. and R.B.H.I.; investigation, S.B.S.; resources, S.R.C., N.M.H., R.B.H.I., M.F.B.M.B., Y.T., Y.H., R.B.A.R. and N.H.B.M.Y.; data curation, S.B.S., S.R.C., N.M.H. and R.B.H.I; writing-original draft preparation, S.B.S., S.R.C., N.M.H.; writing-review and editing, S.B.S., N.M.H.; visualization, S.B.S.; supervision, N.M.H., Y.T., Y.H., R.B.A.R. and N.H.B.M.Y.; project administration, N.M.H., R.B.H.I, M.F.B.M.B., Y.T., Y.H., R.B.A.R. and N.H.B.M.Y.; funding acquisition, N.M.H. and R.B.H.I. All authors have read and agreed to the published version of the manuscript.

Funding: This research was funded by The National University of Malaysia research grant FF-2019198 and DIP-2015-025.

Institutional Review Board Statement: The study was conducted according to the guidelines of the Declaration of Helsinki, and approved by the Research Ethics Committee, The National University of Malaysia (UKM PPI/111/8/JEP-2018-458, 11 October 2018).

Informed Consent Statement: Informed consent was obtained from all subjects involved in the study.

Data Availability Statement: Not applicable. 
Acknowledgments: The authors would like to thank The National University of Malaysia for providing research facilities and research grants.

Conflicts of Interest: The authors declare no conflict of interest.

\section{References}

1. Maumus, M.; Pers, Y.-M.; Ruiz, M.; Jorgensen, C.; Noel, D. Mesenchymal stem cells and regenerative medicine: Future perspectives in osteoarthritis. Med. Sci. 2018, 34, 1092-1099.

2. Vos, T.; Flaxman, A.D.; Naghavi, M.; Lozano, R.; Michaud, C.; Ezzati, M.; Shibuya, K.; Salomon, J.A.; Abdalla, S.; Aboyans, V.; et al. Years lived with disability (YLDs) for 1160 sequelae of 289 diseases and injuries 1990-2010: A systematic analysis for the Global Burden of Disease Study 2010. Lancet 2012, 380, 2163-2196. [CrossRef]

3. Zhang, W.; Moskowitz, R.W.; Nuki, G.; Abramson, S.; Altman, R.D.; Arden, N.; Bierma-Zeinstra, S.; Brandt, K.D.; Croft, P.; Doherty, M.; et al. OARSI recommendations for the management of hip and knee osteoarthritis, Part II: OARSI evidence-based, expert consensus guidelines. Osteoarthr. Cartil. 2008, 16, 137-162. [CrossRef] [PubMed]

4. Katz, J.N.; Earp, B.E.; Gomoll, A.H. Surgical management of osteoarthritis. Arthritis Care Res. 2010, 62, 1220-1228. [CrossRef] [PubMed]

5. Yubo, M.; Yanyan, L.; Li, L.; Tao, S.; Bo, L.; Lin, C. Clinical efficacy and safety of mesenchymal stem cell transplantation for osteoarthritis treatment: A meta-analysis. PLoS ONE 2017, 12, e0175449. [CrossRef] [PubMed]

6. Jevotovsky, D.S.; Alfonso, A.R.; Einhorn, T.A.; Chiu, E.S. Osteoarthritis and stem cell therapy in humans: A systematic review. Osteoarthr. Cartil. 2018, 26, 711-729. [CrossRef]

7. Jo, C.H.; Lee, Y.G.; Shin, W.H.; Kim, H.; Chai, J.W.; Jeong, E.C.; Kim, J.E.; Shim, H.; Shin, J.S.; Shin, I.S.; et al. Intra-articular injection of mesenchymal stem cells for the treatment of osteoarthritis of the knee: A proof-of-concept clinical trial. Stem Cells J. 2014, 32, 1254-1266. [CrossRef]

8. Pers, Y.M.; Rackwitz, L.; Ferreira, R.; Pullig, O.; Delfour, C.; Barry, F.; Sensebe, L.; Cyteval, C.; Lisignoli, G.; Scrauth, J.; et al. Adipose mesenchymal stromal cell-based therapy for severe osteoarthritis of the knee: A phase I dose-escalation Trial. Stem Cells Transl. Med. 2016, 5, 847-856. [CrossRef]

9. Boberg, E.; von Bahr, L.; Afram, G.; Lindström, C.; Ljungman, P.; Heldring, N.; Petzelbauer, P.; Legert, K.G.; Kadri, N.; Le Blanc, K.; et al. Treatment of chronic GvHD with mesenchymal stromal cells induces durable responses: A phase II study. Stem Cells Transl. Med. 2020, 9, 1190-1202. [CrossRef]

10. Kim, C.; Keating, A. Cell therapy for knee osteoarthritis: Mesenchymal stromal cells. Gerontology 2019, 65, 294-298. [CrossRef]

11. Contessi Negrini, N.; Lipreri, M.V.; Tanzi, M.C.; Farè, S. In vitro cell delivery by gelatin microspheres prepared in water-in-oil emulsion. J. Mater. Sci. Mater. Med. 2020, 31, 26. [CrossRef] [PubMed]

12. Im, G.I.; Kim, T.K. Regenerative therapy for osteoarthritis: A perspective. Int. J. Stem Cells 2020, 13, 177. [CrossRef] [PubMed]

13. Mancuso, P.; Raman, S.; Glynn, A.; Barry, F.; Murphy, J.M. Mesenchymal stem cell therapy for osteoarthritis: The critical role of the cell secretome. Front. Bioeng. Biotechnol. 2019, 7, 9. [CrossRef]

14. Park, Y.B.; Ha, C.W.; Lee, C.H.; Yoon, Y.C.; Park, Y.G. Cartilage regeneration in osteoarthritic patients by a composite of allogeneic umbilical cord blood-derived mesenchymal stem cells and hyaluronate hydrogel: Results from a clinical trial for safety and proof-of-concept with 7 years of extended follow-up. Stem Cells Transl. Med. 2017, 6, 613-621. [CrossRef] [PubMed]

15. Murphy, J.M.; Fink, D.J.; Hunziker, E.B.; Barry, F.P. Stem cell therapy in a caprine model of osteoarthritis. Arthritis Rheum. 2003, 48, 3464-3474. [CrossRef] [PubMed]

16. Tharmalingam, T.; Sunley, K.; Spearman, M.; Butler, M. Enhanced production of human recombinant proteins from CHO cells grown to high densities in macroporous microcarriers. Mol. Biotechnol. 2011, 49, 263-276. [CrossRef]

17. Kang, S.W.; Jeon, O.; Kim, B.S. Poly (lactic-co-glycolic acid) microspheres as an injectable scaffold for cartilage tissue engineering. Tissue Eng. 2005, 11, 438-447. [CrossRef]

18. Kang, S.W.; Yoon, J.R.; Lee, J.S.; Kim, H.J.; Lim, H.W.; Lim, H.C.; Park, J.H.; Kim, B.S. The use of poly (lactic-co-glycolic acid) microspheres as injectable cell carriers for cartilage regeneration in rabbit knees. J. Biomater. Sci. Polym. Ed. 2006, 17, 925-939. [CrossRef]

19. García Cruz, D.M.; Sardinha, V.; Escobar Ivirico, J.L.; Mano, J.F.; Gómez Ribelles, J.L. Gelatin microparticles aggregates as three-dimensional scaffolding system in cartilage engineering. J. Mater. Sci. Mater. Med. 2013, 24, 503-513. [CrossRef]

20. Sulaiman, S.; Chowdhury, S.R.; Fauzi, M.B.; Rani, R.A.; Yahaya, N.H.M.; Tabata, Y.; Hiraoka, Y.; Binti Haji Idrus, R.; Min Hwei, N. 3D culture of MSCs on a gelatin microsphere in a dynamic culture system enhances chondrogenesis. Int. J. Mol. Sci. 2020, 21, 2688. [CrossRef]

21. Conaghan, P.G.; Hunter, D.J.; Cohen, S.B.; Kraus, V.B.; Berenbaum, F.; Lieberman, J.R.; Jones, D.G.; Spitzer, A.I.; Jevsevar, D.S.; Katz, N.P.; et al. Effects of a single intra-articular injection of a microsphere formulation of triamcinolone acetonide on knee osteoarthritis pain: A double-blinded, randomized, placebo-controlled, multinational study. J. Bone Jt. Surg. 2018, 100, 666-677. [CrossRef] [PubMed]

22. Custódio, C.A.; Mano, J.F. Cell surface engineering to control cellular interactions. Chem. Nano. Mat. 2016, 2, 376-384. [CrossRef]

23. Dennis, J.E.; Cohen, N.; Goldberg, V.M.; Caplan, A.I. Targeted delivery of progenitor cells for cartilage repair. J. Orthop. Res. 2004, 22, 735-741. [CrossRef] 
24. Lo, C.Y.; Weil, B.R.; Palka, B.A.; Momeni, A.; Canty, J.M.; Neelamegham, S. Cell surface glycoengineering improves selectinmediated adhesion of mesenchymal stem cells (MSCs) and cardiosphere-derived cells (CDCs): Pilot validation in porcine ischemia-reperfusion model. Biomaterials 2016, 74, 19-30. [CrossRef]

25. Dominici, M.; Le Blanc, K.; Mueller, I.; Slaper-Cortenbach, I.; Marini, F.; Krause, D.S.; Deans, R.J.; Keating, A.; Prockop, D.J.; Horwitz, E.M. Minimal criteria for defining multipotent mesenchymal stromal cells. The International Society for Cellular Therapy position statement. Cytotherapy 2006, 8, 315-317. [CrossRef]

26. Hayashi, K.; Tabata, Y. Preparation of stem cell aggregates with gelatin microspheres to enhance biological functions. Acta Biomater. 2011, 7, 2797-2803. [CrossRef]

27. Ozeki, M.; Tabata, Y. In vivo degradability of hydrogels prepared from different gelatins by various cross-linking methods. J. Biomater. Sci. Polym. Ed. 2005, 16, 549-561. [CrossRef] [PubMed]

28. Ude, C.C.; Sulaiman, S.B.; Min-Hwei, N.; Hui-Cheng, C.; Ahmad, J.; Yahaya, N.M.; Saim, A.B.; Idrus, R.B. Cartilage regeneration by chondrogenic induced adult stem cells in osteoarthritic sheep model. PLoS ONE 2014, 9, e98770. [CrossRef]

29. Hafez, P.; Jose, S.; Chowdhury, S.R.; Ng, M.H.; Ruszymah, B.H.I.; Abdul Rahman Mohd, R. Cardiomyogenic differentiation of human sternal bone marrow mesenchymal stem cells using a combination of basic fibroblast growth factor and hydrocortisone. Cell Biol. Int. 2016, 40, 55-64. [CrossRef] [PubMed]

30. Ude, C.C.; Shamsul, B.S.; Ng, M.H.; Chen, H.C.; Ohnmar, H.; Amaramalar, S.N.; Rizal, A.R.; Johan, A.; Norhamdan, M.; Azizi, M.; et al. Long-term evaluation of osteoarthritis sheep knee, treated with TGF- $\beta 3$ and BMP-6 induced multipotent stem cells. Exp. Gerontol. 2018, 104, 43-51. [CrossRef]

31. He, X.T.; Wang, J.; Li, X.; Yin, Y.; Sun, H.H.; Chen, F.M. The critical role of cell homing in cytotherapeutics and regenerative medicine. Adv. Ther. 2019, 2, 1800098. [CrossRef]

32. Aicart-Ramos, C.; Valero, R.A.; Rodriguez-Crespo, I. Protein palmitoylation and subcellular trafficking. Biochim. Biophys. Acta Biomembr. 2011, 1808, 2981-2994. [CrossRef] [PubMed]

33. Akerström, B.; Brodin, T.H.; Reis, K.; Björck, L. Protein G: A powerful tool for binding and detection of monoclonal and polyclonal antibodies. J. Immunol. 1985, 135, 2589-2592. [PubMed]

34. Ko, I.K.; Kean, T.J.; Dennis, J.E. Targeting mesenchymal stem cells to activated endothelial cells. Biomaterials 2009, 30, 3702-3710 [CrossRef] [PubMed]

35. Eyre, D. Collagen of articular cartilage. Arthritis Res. 2002, 4, 30-35. [CrossRef] [PubMed]

36. Chen, A.; Zheng, G.; Tykocinski, M.L. Hierarchical costimulator thresholds for distinct immune responses: Application of a novel two-step Fc fusion protein transfer method. J. Immunol. 2000, 164, 705-711. [CrossRef]

37. Sun, X.; Zhang, G.; Patel, D.; Stephens, D.; Gobin, A.M. Targeted cancer therapy by immunoconjugated gold-gold sulfide nanoparticles using Protein G as a cofactor. Ann. Biomed. Eng. 2012, 40, 2131-2139. [CrossRef]

38. Centi, S.; Ratto, F.; Tatini, F.; Lai, S.; Pini, R. Ready-to-use protein G-conjugated gold nanorods for biosensing and biomedical applications. J. Nanobiotechnol. 2018, 16, 1-11. [CrossRef]

39. Hubka, K.M.; Dahlin, R.L.; Meretoja, V.V.; Kasper, F.K.; Mikos, A.G. Enhancing chondrogenic phenotype for cartilage tissue engineering: Monoculture and coculture of articular chondrocytes and mesenchymal stem cells. Tissue Eng. Part B Rev. 2014, 20, 641-654. [CrossRef]

40. Schnabel, M.; Marlovits, S.; Eckhoff, G.; Fichtel, I.; Gotzen, L.; Vecsei, V.; Schlegel, J. Dedifferentiation-Associated changes in morphology and gene expression in primary human articular chondrocytes in cell culture. Osteoarthr. Cartil. 2002, 10, 62-70. [CrossRef]

41. Von der Mark, K.; Gauss, V.; von der Mark, H.; Muller, P. Relationship between cell shape and type of collagen synthesised as chondrocytes lose their cartilage phenotype in culture. Nature 1977, 267, 531-532. [CrossRef] [PubMed]

42. Giovannini, S.; Diaz-Romero, J.; Aigner, T.; Mainil-Varlet, P.; Nesic, D. Population doublings and percentage of S100-positive cells as predictors of in vitro chondrogenicity of expanded human articular chondrocytes. J. Cell Physiol. 2010, 222, 411-420. [CrossRef]

43. Leong, W.; Lau, T.T.; Wang, D.A. A temperature-Cured dissolvable gelatin microsphere-based cell carrier for chondrocyte delivery in a hydrogel scaffolding system. Acta Biomater. 2013, 9, 6459-6467. [CrossRef] [PubMed]

44. Stefani, R.M.; Lee, A.J.; Tan, A.R.; Halder, S.S.; Hu, Y.; Guo, X.E.; Stoker, A.M.; Ateshian, G.A.; Marra, K.G.; Cook, J.L.; et al. Sustained low-dose dexamethasone delivery via a PLGA microsphere-embedded agarose implant for enhanced osteochondral repair. Acta Biomater. 2020, 102, 326-340. [CrossRef] [PubMed]

45. Tan, H.; Huang, D.; Lao, L.; Gao, C. RGD modified PLGA/gelatin microspheres as microcarriers for chondrocyte delivery. J. Biomed. Mater. Res. B Appl. Biomater. 2009, 91, 228-238. [CrossRef] 